\title{
Olfactory behavior and response of household ants (Hymenoptera) to different types of coffee odor: A coffee-based bait development prospect
}

\author{
Abdul Hafiz Ab Majid ${ }^{a, *}$, Hamady Dieng ${ }^{\mathrm{b}}$, Siti Salbiah Ellias ${ }^{\mathrm{a}}$, Faezah Syukriah Sabtu ${ }^{\mathrm{a}}$, \\ Abd Hafis Abd Rahim ${ }^{a}$, Tomomitsu Satho ${ }^{c}$

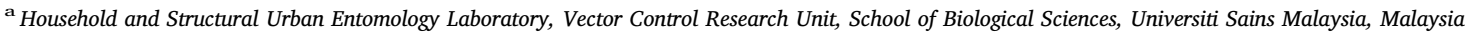 \\ ${ }^{\mathrm{b}}$ Institute of Biodiversity and Environmental Conservation, Universiti Malaysia Sarawak, 94300 Kota Samarahan, Sarawak, Malaysia \\ ${ }^{\mathrm{c}}$ Department of Microbiology, Faculty of Pharmaceutical Sciences, Fukuoka University, 8-19-1 Nanakuma, Johan-ku, 814-0180 Fukuoka, Japan
}

\section{A R T I C L E I N F O}

\section{Keywords:}

Household ants

Olfactory

Coffee

Behavioral effects

\begin{abstract}
A B S T R A C T
Odor sensation is a sensory modality of considerable significance in the foraging behavior and interactional organization of ants. In the food bait technology, smell is the basis of attraction, which, in turn, is the line of bait use and a key parameter for judging efficacy. Yet, the currently available baits possess low attractiveness to many ant pests. Hence, strategies to produce ant bait with increased attractiveness are needed. Despite evidence that coffee has a diverse aroma complex that affects the behavior of honey bees and ants, its attraction to houseinvading ants has yet to be investigated. In a series of Y-tube olfactometer bioassays, we examined the behavioral responses of Tapinoma indicum (TI), Monomorium pharaonis (MP) and Solenopsis geminata (SG) to various coffeeinduced odor stimuli, comprised of extracts from Arabica, Robusta and Liberica. All coffee extracts showed an influence on the behavior of TI, MP and SG workers, with Arabica showed the most significant influence to the tested ants. The workers of TI, MP and SG were more attracted to the odor of $0.01 \%$ Arabica extract (ONE), in comparison with $0.05 \%$ Arabica extract (TWO) or $0.10 \%$ Arabica extract (THREE). Arabica extract mixed with sugar (S) elicited a significant attraction from workers of all three species in a balanced competition with either unsweetened Arabica extract or water. These results indicated that coffee, particularly Arabica, was attractive to the foragers of TI, MP and SG, thus, the use of coffee as a novel stimulus agent seems plausible in ant bait development.
\end{abstract}

\section{Introduction}

There are $>12,000$ known species of ants (Hammond, 2011), many of which are among the most common insects invading or living inside human establishments where they become a nuisance and cause damage (Lee, 2002). The typical house invaders are dolichoderine ants such as Tapinoma indicum (Lee, 2002; Man and Lee, 2014), Monomorium pharaonis (Osae et al., 2011) and Solenopsis geminata (Harris et al., 2005).

Among the species, T. indicum is the most nuisance, having the ability to invade any disturbed habitats suitable for its nesting and subsequently forms large-sized colonies (Passera, 1994). Another house-invading ant species, M. pharaonis (also known as the Pharaoh ants), attacks a wide range of foodstuffs, clothes, and books (Dumpert, 1981). This species is also able to chew on silk, rayon, rubber and electrical wiring (Hölldobler and Wilson, 1990). In hospitals, the Pharaoh ant is reputed to carry several pathogenic bacteria (Haack and
Granovsky, 1990; Smith and Whitman, 1992) and may feed on wounds (Anon, 1986), thus, considered as a potential disease vector (Osae et al., 2011). S. geminata, on the other hand, is a major threat to agricultural crops (Wilson, 2005), affecting farmers' performance by inflicting irritating stings (Hill, 1987; Nestel and Dickschen, 1990). This type of ant also causes substantial damage to PVC coatings of electrical wiring (Prins, 1985) and drip irrigation tubing (Chang and Ota, 1990).

Efforts to combat such damages rely heavily on the use of chemical insecticides through baiting (Higgins et al., 1997), residual perimeter sprays (Potter and Hillery, 2002), or both (Higgins et al., 1997). In these global strategies against ant pests, baiting forms a very crucial part of the solution (Jordan et al., 2013). This method takes advantage of the social trophallactic and grooming behaviors of ants (Lee, 2008) and relies on the pick-up of bait particles by foraging workers and their transfers to other colony members (Jordan et al., 2013). Baits have been successfully used to control a number of social insect pests (Jordan et al., 2013). However, many bait-based programs are failed due to

\footnotetext{
* Corresponding author at: Household and Structural Urban Entomology Laboratory, School of Biological Sciences, Universiti Sains Malaysia, Penang, Malaysia.

E-mail address: abdhafiz@usm.my (A.H. Ab Majid).
} 